Jurnal Riset Agama

Volume 1, Nomor 2 (Agustus 2021): 439-448

DOI: $10.15575 /$ jra.v1i2.14728

https://journal.uinsgd.ac.id/index.php/jra

\title{
Itsmid sebagai Eyeliner dalam Kosmetika Dunia Muslim: Studi Takhrij dan Syarah Hadis
}

\author{
Syfa Nurhofipah \\ Jurusan Ilmu Al-Qur'an dan Tafsir, Fakultas Ushuluddin, \\ UIN Sunan Gunung Djati Bandung, Indonesia \\ syfanurhofipah@gmail.com
}

\begin{abstract}
This study aims to discuss the hadith related to eyeliner. This study uses a qualitative approach through the method of takhrij and syarah hadith analysis of contemporary issues. The results of this study found that the hadith about itsmid is closely related to eyeliner in the contemporary era. The quality status of itsmid hadith is considered authentic so that it can be used as a basis for Islamic practice. The discussion of this study explains that eyeliner has been found since the time of the Prophet known as eye shadow (al-itsmid) as a health to grow eyelashes in addition to sharpening the eyes. While eyeliner in the contemporary era is more used for the beauty of women and the use of eye shadow is more as make up. The conclusion of this study is that the use of eyeliner in the contemporary era is more susceptible to health than eye shadow made from alitsmid. This study recommends millennials, especially women, to use make-up that is sterile and safe for health.
\end{abstract}

Keywords: Eyeliner; Hadith; Itsmid.

\begin{abstract}
Abstrak
Penelitian ini bertujuan membahas hadis terkait eyeliner. Penelitian ini menggunakan pendekatan kualitatif melalui metode takhrij dan syarah hadis analisis isu kontemporer. Hasil penelitian ini menemukan bahwa hadis tentang itsmid erat kaitannya dengan eyeliner di era kontemporer. Status kualitas hadis itsmid dinilai shahih sehingga dapat dijadikan landasan untuk amalan Islam. Pembahasan penelitian ini menjelaskan bahwa eyeliner telah ditemukan sejak di masa Rasulullah yang dikenal dengan celak mata (al-itsmid) sebagai kesehatan untuk menumbuhkan bulu mata selain untuk mempertajam mata. Sedangkan eyeliner di era kontemporer lebih digunakan untuk kecantikan kaum perempuan dan penggunaan celak mata lebih sebagai make up. Kesimpulan penelitian ini adalah penggunaan
\end{abstract}


Jurnal Riset Agama, Volume 1, Nomor 2 (Agustus 2021): 439-448

Syfa Nurhofipah/Itsmid sebagai Eyeliner dalam Kosmetika Dunia Muslim: Studi

Takhrij dan Syarah Hadis

eyeliner di era kontemporer rentan terhadap kesehatan dibanding celak mata yang terbuat dari al-itsmid. Penelitian ini merekomendasikan kepada kaum millenial khususnya para wanita agar menggunakan make up yang steril dan aman bagi kesehatan.

Kata kunci: Eyeliner; Hadis; Itsmid.

\section{Pendahuluan}

Menurut Ibnu Hajar, itsmid adalah batu yang berwarna hitam yang biasa digunakan untuk memukul batu besar yang terdapat di dataran Hijaz. Batu Itsmid yang paling bagus adalah yang berasal dari Isfahan (Ulfa, 2014). Jika ditinjau dari ilmu kesehatan, itsmid memiliki manfaat yaitu : pertama, bercelak dengan itsmid dapat membunuh bakteri, kuman dan mikroorganisme lain yang berbahaya yang terdapat di dalam kelopak mata. Kedua, bercelak dengan itsmid dapat menyegarkan kulit dan merangsang pertumbuhan bulu mata. Seperti gatal-gatal dan alergi (Ulfa, 2014). Kalangan wanita saat ini sering menyebutnya eyeliner. Tetapi eyeliner biasanya tidak diproduksi dengan menggunakan bahan baku yang steril dan dibuat dalam kondisi aseptik, walaupun pengawet sering ditambahkan untuk mengurangi kontaminan, tetap dapat terkontaminasi ketika sampai ke tangan konsumen (Habiba M. Assegaf, Christina Avanti, 2018). Dan eyeliner sendiri belum tentu terbuat dari itsmid. Fungsi celak pun sudah berubah menjadi bagian dari alat make up khususnya bagi perempuan (Ulfa, 2014). Oleh karena itu, perlu dilakukan kajian terhadap hadis Nabi SAW terkait eyeliner.

Sejumlah ahli telah melakukan penelitian terkait dengan eyeliner sebagaimana dalam tinjauan pustaka ini. Di antaranya Suparjan \& Aisyah (2020), "Pengguna Eyelash Extension bagi Perempuan Muslimah Perspektif Hukum Islam (Studi Kasus Salon di Kota Makassar)," Universitas Islam Negeri Alauddin Makassar. Penelitian ini membahas tentang bagaimana perempuan muslimah yang menggunakan eyelash extension. Jenis penelitian ini menggunakan metode deskriptif kualitatif yaitu suatu penelitian yang dilakukan di lingkungan masyarakat. Lokasi penelitian di kota Makasar, yaitu yang meliputi salon Inner-V Hair \& Beauty, Elslashpro dan Nilaeyelash. Hasil dari penelitian ini adalah terdapat faktor yang menyebabkan perempuan menggunakan eyelash extension ialah yang pertama, ingin terlihat cantik dan tampil lebih percaya diri. Kedua, perempuan lebih menghemat waktu dan biaya karena perempuan tidak lagi menghabiskan waktu yang lama untuk mengurusi hiasan pada matanya dan menghemat biaya untuk membeli 
Jurnal Riset Agama, Volume 1, Nomor 2 (Agustus 2021): 439-448

Syfa Nurhofipah/Itsmid sebagai Eyeliner dalam Kosmetika Dunia Muslim: Studi

Takhrij dan Syarah Hadis

alat riasan mata (Suparjan \& Aisyah, 2020). Intan, T. R., \& Dindy, S. M. (2014), "Pengaruh Pengaplikasian Teknik Eyeliner terhadap Hasil Riasan Koreksi Mata Prominent Eyes untuk Pengantin Muslim Modifikasi," Universitas Negeri Surabaya. Penelitian ini bertujuan untuk mengetahui pengaruh dari pengaplikasian teknik eyeliner pada koreksi mata prominent eyes untuk pengantin muslim modifikasi dan mengetahui mana yang terbaik di antara tightline eyeliner dan classic eyeliner pada koreksi mata prominent eyes untuk pengantin muslim modifikasi. Pendekatan yang digunakan pada penelitian ini yaitu pendekatan kuantitatif. Hasil penelitian ini terdapat pengaruh pengaplikasian teknik tightline eyeliner dan classic eyeliner pada hasil riasan koreksi mata prominent eyes untuk pengantin muslim modifikasi berdasarkan nilai Asymp. Sig. Sebesar 0,000 $<0,05$ maka dapat disimpulkan bahwa hipotesis diterima, dan hasil ratarata tightline eyeliner sebesar 3,75 dan classic eyeliner 3,38 jadi kesimpulannya yaitu riasan terbaik adalah tightline eyeliner (Intan Tri Yuniari, 2020). Waliko (2015), “Konsep Iddah dan Ihdah bagi Wanita Karier yang Ditinggal Mati Suaminya (Tinjauan Ma'anil Hadits)," IAIN Purwakerto. Penelitian ini menggunakan pendekatan historis, sosiologis dan psikologis, dengan menyajikan bahasan tentang cara Nabi memosisikan perempuan lewat rekaman hadits tentang berkabungnya seorang istri. Hasil penelitian ini ada dua hal yang harus dijalankan seorang muslimah ketika dia ditinggal mati suaminya yaitu iddah dan ihdah yang batasannya adalah empat bulan sepuluh hari bagi yang tidak hamil dan setelah melahirkan bagi yang hamil. Termasuk bercelak mata juga dilarang bagi wanita yang ditinggal mati oleh suaminya, sekalipun untuk mengobati mata yang sakit (Waliko, 2015).

Menindak lanjuti tinjauan di atas, disusun suatu kerangka berpikir bahwa Eyeliner selalu digunakan untuk memperindah mata sehingga memberi kesan lebih dramatis dan ekspresif. Fungsi eyeliner yaitu dapat mengubah mata yang kecil menjadi besar dan sebaliknya (Intan Tri Yuniari, 2020). Hadis merupakan sumber ajaran Islam yang kedua setelah Al-Quran. Di dalam Al-Quran tentu tidak ada permasalahan yang signifikan. Hal ini dikarenakan Al-Quran merupakan kalam Allah SWT yang diturunkan kepada Nabi Muhammad SAW. Berbeda dengan hadis, di dalam memahaminya banyak persoalan yang harus dikaji, baik dari segi periwayatan (sanad) maupun isi hadis tersebut. Oleh karena itu, perlu adanya penelitian di dalam menentukan kualitas hadis yang sahih (Qomarullah, 2016). Takhrij hadis adalah proses atribusi (proses deskripsi) suatu hadis hingga sampai pada kolektor hadisnya. Tujuan dari takhrij hadis secara garis besar adalah untuk menunjukan sumber-sumber hadis dan menerangkan diterima atau ditolaknya hadis tersebut (M. Hafil Birbik, 2020). 
Jurnal Riset Agama, Volume 1, Nomor 2 (Agustus 2021): 439-448

Syfa Nurhofipah/Itsmid sebagai Eyeliner dalam Kosmetika Dunia Muslim: Studi

Takhrij dan Syarah Hadis

Berdasarkan paparan di atas, formula penelitian disusun, yaitu rumusan masalah, pertanyaan utama penelitian, dan tujuan penelitian (Darmalaksana, 2020a). Rumusan masalah penelitian ini adalah terdapat hadis itsmid terkait eyeliner. Pertanyaan penelitian ini ialah bagaimana teks hadis itsmid terkait eyeliner. Tujuan penelitian ini membahas hadis itsmid terkait eyeliner. Penelitian ini diharapkan menambah pengetahuan Islam, terutama bagi wanita dalam berhias.

\section{Metode Penelitian}

Metode penelitian ini menggunakan jenis pendekatan kualitatif melalui studi pustaka (Darmalaksana, 2020b). Penelitian ini menerapkan metode takhrij dan syarah hadis (Darmalaksana, 2020d). Pada hadis yang berkenaan dengan eyeliner melalui analisis kontemporer (Darmalaksana, 2020c).

\section{Hasil dan Pembahasan}

Hasil dan pembahasan di bawah ini.

\section{Redaksi Teks Hadis}

Berdasarkan penelusuran hadis pada aplikasi Ensiklopedi Hadis Kitab 9 Imam ditemukan hadis Riwayat Imam an-Nasa'i Bab Celak versi al-Alamiah No. 5024 dan versi Maktabatu al-Ma'arif Riyadh No. 5113 (Saltanera, 2015). Adapun redaksi teks hadis di bawah ini:

$$
\begin{aligned}
& \text { أخبرنا قتيبة قال حدثنا داود وهو ابن عبد الرحمن العطار عن عبد الله بن عثمان بن خثيم عن } \\
& \text { سعيد بن جبير عن ابن عباس } \\
& \text { أن رسول الله صلى الله عليه وسلم قال إن من خير أكحالكم الإثمد إنه يجلو البصر وينبت الشعر }
\end{aligned}
$$

Telah menceritakan kepada kami Qutaibah ia berkata; telah menceritakan kepada kami Daud yaitu Ibnu 'Abdurrahman al-'Aththardari Abdullah bin Utsman bin Khutsaim dari Sa'id bin Jubair dari Ibnu Abbas bahwa Rasullulah SAW bersabda, "Sesungguhnya celak terbaik untuk kalian pakai adalah al-itsmid (batu celak), ia bisa membuat tajam pandangan mata dan menumbuhkan rambut"'(Saltanera, 2015).

\section{Takhrij Hadis}

Takhrij hadis itsmid terkait eyeliner ditampilkan dalam bentuk tabel berikut.

Tabel 1. Daftar Rawi Sanad

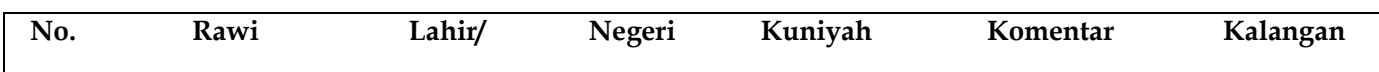


Jurnal Riset Agama, Volume 1, Nomor 2 (Agustus 2021): 439-448

Syfa Nurhofipah/Itsmid sebagai Eyeliner dalam Kosmetika Dunia Muslim: Studi Takhrij dan Syarah Hadis

\begin{tabular}{|c|c|c|c|c|c|c|c|}
\hline & \multirow[t]{2}{*}{ Sanad } & \multicolumn{2}{|c|}{ Wafat } & & \multicolumn{3}{|c|}{ Ulama } \\
\hline & & $\mathbf{L}$ & $\mathbf{W}$ & & & + & \\
\hline 1 & $\begin{array}{l}\text { Abdullah bin } \\
\text { 'Abbas bin } \\
\text { 'Abdul } \\
\text { Muthallib bin } \\
\text { Hasyim }\end{array}$ & & $68 \mathrm{H}$ & $\begin{array}{l}\text { Marur } \\
\text { Rawdz }\end{array}$ & $\begin{array}{l}\text { Abu al- } \\
\text { 'Abbas }\end{array}$ & $\begin{array}{l}\text { Ibnu Hajar al- } \\
\text { Atsqalani: } \\
\text { Shahabat; } \\
\text { Adz Dzahabi: } \\
\text { Shahabat }\end{array}$ & Shahabat \\
\hline 2 & $\begin{array}{l}\text { Sa'id Jubair bin } \\
\text { Hisyam }\end{array}$ & & $94 \mathrm{H}$ & Kuffah & $\begin{array}{l}\text { Abu } \\
\text { Muhammad }\end{array}$ & $\begin{array}{l}\text { Ibnu Hibban: } \\
\text { Disebutkan } \\
\text { dalam ats- } \\
\text { tsiqat; } \\
\text { Adz Dzahabi: } \\
\text { Ahadul A'lam, } \\
\text { Yahya bin } \\
\text { Ma'in: Tsiqah; } \\
\text { Abu Zur'ah } \\
\text { Arrazy: } \\
\text { Tsiqah; } \\
\text { Ibnu Hajar al- } \\
\text { Asqalani: } \\
\text { Tsiqah tsabat } \\
\text { faqih }\end{array}$ & $\begin{array}{l}\text { Tabi'in } \\
\text { kalangan } \\
\text { pertengahan }\end{array}$ \\
\hline 3 & $\begin{array}{l}\text { Abdullah bin } \\
\text { ‘Utsman bin } \\
\text { Khutsaim }\end{array}$ & & $\begin{array}{c}132 \\
\mathrm{H}\end{array}$ & $\begin{array}{l}\text { Marur } \\
\text { Rawdz }\end{array}$ & $\begin{array}{l}\text { Abu } \\
\text { ‘Utsman }\end{array}$ & $\begin{array}{l}\text { Yahya bin } \\
\text { Ma'in: Tsiqah } \\
\text { Hujjah; } \\
\text { Al-'Ajli: } \\
\text { Tsiqah; } \\
\text { An-Nasa'i: } \\
\text { Tsiqah; } \\
\text { Abu Hatim: } \\
\text { Shalihul } \\
\text { Hadits, } \\
\text { Ibnu Hibban: } \\
\text { Disebutkan } \\
\text { dalam 'ats- } \\
\text { tsiqat, } \\
\text { Ibnu Hajar al- } \\
\text { Atsqalani: } \\
\text { Shaduq }\end{array}$ & $\begin{array}{l}\text { Tabi'in } \\
\text { kalangan } \\
\text { biasa }\end{array}$ \\
\hline 4 & $\begin{array}{l}\text { Daud bin } \\
\text { ‘Abdurrahman }\end{array}$ & & $\begin{array}{c}174 \\
\mathrm{H}\end{array}$ & $\begin{array}{l}\text { Marur } \\
\text { Rawdz }\end{array}$ & $\begin{array}{l}\text { Abu } \\
\text { Sulaiman }\end{array}$ & $\begin{array}{l}\text { Al-'Ajil: } \\
\text { Tsiqah; } \\
\text { Yahya bin } \\
\text { Ma'in: Tsiqah; } \\
\text { Abu Dawud } \\
\text { as-Sajastani: }\end{array}$ & $\begin{array}{l}\text { Tabi'ut } \\
\text { Tabi'in } \\
\text { kalangan } \\
\text { pertengahan }\end{array}$ \\
\hline
\end{tabular}


Jurnal Riset Agama, Volume 1, Nomor 2 (Agustus 2021): 439-448

Syfa Nurhofipah/Itsmid sebagai Eyeliner dalam Kosmetika Dunia Muslim: Studi Takhrij dan Syarah Hadis

\begin{tabular}{|c|c|c|c|c|c|c|c|}
\hline & & & & & & $\begin{array}{l}\text { Tsiqah; } \\
\text { Ibnu Hibban: } \\
\text { Disebutkan } \\
\text { dalam ats- } \\
\text { tsiqat; } \\
\text { Al-Bazzar: } \\
\text { Mentsiqahkan } \\
\text { nya, } \\
\text { Abu Hatim ar- } \\
\text { Rozy: } \\
\text { Mentsiqahkan } \\
\text { nya }\end{array}$ & \\
\hline 5 & $\begin{array}{l}\text { Qutaibah bin } \\
\text { Sa'id bin Jamil } \\
\text { bin Tharif bin } \\
\text { 'Abdullah }\end{array}$ & & $\begin{array}{c}240 \\
\mathrm{H}\end{array}$ & Himsh & Abu Raja' & $\begin{array}{l}\text { Abu Hatim: } \\
\text { Tsiqah; } \\
\text { An-Nasa'i: } \\
\text { Tsiqah; } \\
\text { Yahya bin } \\
\text { Ma'in: Tsiqah; } \\
\text { Ibnu Hajar al- } \\
\text { 'Asqalani: } \\
\text { Tsiqah Tsabat }\end{array}$ & $\begin{array}{l}\text { Tabi'ul } \\
\text { Atba' } \\
\text { kalangan } \\
\text { tua }\end{array}$ \\
\hline 6 & $\begin{array}{l}\text { Ahmad bin } \\
\text { Syu'aib al- } \\
\text { Khurasany } \\
\text { Imam an-Nasa'i }\end{array}$ & $\begin{array}{c}215 \\
\mathrm{H}\end{array}$ & $\begin{array}{c}300 \\
\mathrm{H}\end{array}$ & & $\begin{array}{l}\text { Ahmad al- } \\
\text { Khurasany }\end{array}$ & Imam Hadis & Mudawwin \\
\hline
\end{tabular}

Tabel 1 merupakan rawi dan sanad hadis riwayat Imam an-Nasa'i Bab Celak. Pada tabel tersebut terdapat matrik Rawi-Sanad, Tahun Lahir dan Wafat, Negeri, Kuniyah (panggilan), Komentar Ulama, dan Kalangan. Hadis ini diriwayatkan oleh 6 (enam) orang rawi (periwayat), sejak asal sanad (rawi pertama) yaitu Abdullah bin 'Abbas bin 'Abdul Muthallib bin Hasyim (kalangan Shahabat) sampai mudawwin (rawi terakhir) yakni Ahmad bin Syu'aib al-Khurasany yang dikenal an-Nasa'i (215-300 H). Semua rawi diketahui kuniyahnya dan ada satu dari periwayat yang diketahui kelahirannya. Menurut ilmu hadis, rawi terakhir adalah sanad pertama sedangkan rawi pertama ialah sanad terakhir (Darmalaksana, 2021).

\section{Kualitas Hadis}


Jurnal Riset Agama, Volume 1, Nomor 2 (Agustus 2021): 439-448

Syfa Nurhofipah/Itsmid sebagai Eyeliner dalam Kosmetika Dunia Muslim: Studi

Takhrij dan Syarah Hadis

Hadis dikatakan berkualitas sahih apabila rawi adil dan dhabit, sanad bersambung (muttasil), matan hadis tidak janggal (syadz), dan matan hadis tidak cacat (Darmalaksana, 2018). Menurut Muhammad Nashiruddin al-Albani hadis ini adalah shahih. Pada tabel 1 tampak bahwa banyak para ulama yang memberi komentar positif terhadap para rawi dengan memberi komentar tsigah. Komentar ulama pun sangat beragam cakupannya ada yang menilai positif ( $\left.t a^{\prime} d i l\right)$ dan ada pula yang menilai negatif (jarh) (Darmalaksana, 2021). Rawi yang dinilai tsiqah berarti ia orang yang adil dan kuat hapalannya. Selain tsiqah para ulama memberi komentar ahadul a'lam, tsiqah tsabat, tsiqah tsabat faqih, tsiqah hujjah, shalihul hadis, shaduq. Kemudian tidak ada satu pun komentar ulama yang berkomentar negatif terhadap para rawi tersebut. Maka dapat disimpulkan bahwa rawi dan jalur sanad ini seluruhnya adalah adil dan kuat hapalannya yang dapat mempengaruhi kualitas hadis. Sedangkan syarat sanad bersambung adalah bertemu (liqa') antara guru (yang menyampaikan hadis) dan murid (yang menerima hadis) (Darmalaksana, 2021). Pertemuan guru dan murid dapat diketahui dari masa waktu dan negeri (Darmalaksana, 2021). Masa waktu dilihat dari tahun lahir dan wafat dan negeri dapat menunjukan pertemuan guru dan murid di satu wilayah (Darmalaksana, 2021). Apabila beberapa periwayat tidak diketahui tahun lahir dan wafat, maka para rawi dapat diasumsikan ratarata berusia kurang lebih 90 tahun (Darmalaksana, 2021). Meskipun pada Tabel 1 hanya satu periwayat yang diketahui tahun lahir, namun dengan asumsi tersebut maka periwayat pada jalur sanad Tabel 1 diperkirakan bertemu antara guru dan murid. Dengan kata lain, sanad hadis pada tabel 1 dapat dikatakan bersambung (Darmalaksana, 2021).

Selain dilihat dari penilaian rawi dan sanad, kualitas hadis ditentukan dari segi matan dengan syarat terhindar dari kejanggalan dan cacat. Dan tidak terdapat kejanggalan dan cacat dalam hadis ini maka dari itu dapat disimpulkan hadis riwayat an-Nasa'i No. 5024 dapat dikatakan sebagai hadis yang shahih.

\section{Syarah Hadis Eyeliner}

Syarah hadis secara mutlak adalah syarah terhadap hadis secara lengkap, yaitu mengurai jelaskan ucapan, tindakan dan ketetapan Rasulullah SAW beserta sanadnya (Soetari, 2015). Hadis yang bisa diamalkan (ma'mul) dan hadisnya telah diterima (maqbul) melalui takhrij (Darmalaksana, 2018). Berdasarkan takhrij ditemukan status hadis riwayat an-Nasa'i No. 5024 berkualitas shahih dari sisi tersambungnya sanad dan dari penilaian rawi yang mana hadis tersebut dapat diterima, adil dan dhabit periwayatannya, dan dari segi matannya tidak ada kejanggalan dan cacat (Darmalaksana, 2021). 
Jurnal Riset Agama, Volume 1, Nomor 2 (Agustus 2021): 439-448

Syfa Nurhofipah/Itsmid sebagai Eyeliner dalam Kosmetika Dunia Muslim: Studi

Takhrij dan Syarah Hadis

Hadis riwayat an-Nasa'i No. 5024 memberi keterangan bahwa celak terbaik adalah al-itsmid (batu celak). Al-itsmid juga dapat mempertajam pandangan mata dan menumbuhkan rambut (bulu mata) (Saltanera, 2015).

Menghias diri sehari-hari dilakukan oleh orang pada umumnya, lebih-lebih para wanita. Rambut, wajah, pakaian dan apa saja yang sekiranya akan dilihat oleh orang lain harus dipercantik agar kelihatan indah. Siapa pun akan senang jika disebut indah, pantas, dan cantik. Begitu pula sebaliknya, orang tidak suka disebut banyak kekurangan (Fadila, 2021). Terutama pada mata karena merupakan salah satu indra yang berperan penting bagi manusia mata yang sakit, misalnya belekan akan membuat orang lain menghindar, karena khawatir tertular juga penyakit tersebut. Sedangkan dengan mata yang sehat akan membuat orang lain merasa nyaman (Ulfa, 2014). Murtadha az-Zabidiy mengatakan itsmid adalah batu celak berwarna hitam kemerahan, berasal dari Ashbahan dan juga ada di Maroko namun di Maroko lebih keras, dan itsmid merupakan jenis celak terbaik (Al-Bantani, 2017). Disunnahkan memakai celak sebanyak tiga kali karena inilah yang dicontohkan oleh Nabi SAW (Al-Bantani, 2017). Waktu terbaik untuk bercelak adalah ketika seorang wanita di hadapan suaminya atau mahramnya dan berada di rumah maka diperbolehkan kapanpun ia menginginkannya, namun yang terbaik ketika menjelang tidur (Al-Bantani, 2017). Menurut Ibnu Qayyim, celak dapat menjaga kesehatan mata, memperkuat cahaya mata, membersihkan unsur-unsur yang jelek dan mengeluarkannya dan di antara jenis dan macam-macamnya berfungsi sebagai hiasan dan ketika tidur memiliki kelebihan keutamaan karena mencakup atas celak dan gerakan yang membahayakan (Al-Bantani, 2017). Matan hadis tentang celak bukanlah hal yang janggal. Dalam arti dapat dipahami oleh nalar akal sehat (Darmalaksana, 2021). Dan matan hadis tentang celak pun tidak cacat yakni tidak bertentangan dengan Al-Qur'an dan hadis-hadis lain (Darmalaksana, 2021).

Namun celak yang sekarang berbeda dengan itsmid (Ulfa, 2014) atau yang sering kita sebut eyeliner. Untuk menjamin eyeliner aman dari kontaminasi mikroba maka diperlukan pengawet. Pengawet bertujuan mencegah tumbuhnya, atau untuk bereaksi menghancurkan mikroorganisme yang bisa merusak produk atau tumbuh pada produk (Habiba M. Assegaf, Christina Avanti, 2018). Oleh karena itu, kita harus berhati-hati dalam memilih produk eyeliner. Kita harus lebih mengarahkan pada kesehatan bukan kecantikan (Darmalaksana, 2021).

\section{Kesimpulan}

Eyeliner adalah salah satu make up yang sering kali digunakan oleh para wanita. Dengan menggunakan eyeliner mata terkesan lebih indah dan 
Jurnal Riset Agama, Volume 1, Nomor 2 (Agustus 2021): 439-448

Syfa Nurhofipah/Itsmid sebagai Eyeliner dalam Kosmetika Dunia Muslim: Studi

Takhrij dan Syarah Hadis

berwarna. Dalam Islam, eyeliner sudah ada sejak zaman Rasulullah SAW. Di zaman Rasulullah eyeliner disebut dengan celak mata. Banyak manfaat dari celak mata, salah satunya untuk kesehatan mata. Status kualitas hadis tentang celak mata (itsmid) dinilai shahih berdasarkan takhrij hadis. Dan syarah hadis menunjukan bahwa celak yang terbaik adalah yang terbuat dari al-itsmid yaitu dapat mempertajam mata dan menumbuhkan rambut (bulu mata). Kandungan matan juga tidak bertentangan dengan hadis lain maupun dengan ayat-ayat Al-Qur'an. Dengan demikian hadis riwayat Imam an-Nasa'i dapat dijadikan hujjah. Pemaknaan hadis menunjukan bahwa isi matan hadis mengandung anjuran memakai celak mata yang terbaik yaitu yang terbuat dari al-itsmid. Penelitian ini diharapkan dapat menambah wawasan bagi para wanita dalam memakai produk eyeliner agar lebih mengutamakan kesehatan daripada kecantikan. Penelitian ini memiliki keterbatasan karena hanya menyajikan singkat takhrij dan syarah hadis sehingga perlu penelitian lebih lanjut secara mendalam. Penelitian ini merekomendasikan kepada kaum millenial khususnya para wanita agar menggunakan make up yang steril dan aman bagi kesehatan.

\section{Daftar Pustaka}

Al-Bantani, M. (2017). Fikih Wanita. Mulia.

Darmalaksana, W. (2018). Paradigma Pemikiran Hadis. Jurnal Aqidah Dan Filsafat Islam, 2(1), 95-106.

Darmalaksana, W. (2020a). Formula Penelitian Pengalaman Kelas Menulis. Jurnal Kelas Menulis UIN Sunan Gunung Djati Bandung. http://digilib.uinsgd.ac.id/32620/

Darmalaksana, W. (2020b). Metode Penelitian Kualitatif Studi Pustaka dan Studi Lapangan. Pre-Print Digital Library UIN Sunan Gunung Djati Bandung.

Darmalaksana, W. (2020c). Penelitian Hadis Metode Syarah Pendekatan Kontemporer: Sebuah Panduan Skripsi, Tesis, dan Disertasi. Diroyah: Jurnal Studi Ilmu Hadits, 1(5), 58-68.

Darmalaksana, W. (2020d). Prosiding Proses Bisnis Validitas Hadis untuk Perancangan Aplikasi Metode Tahrij. Jurnal Ushuluddin UIN Sunan Gunung Djati Bandung, 1, 1-7.

Darmalaksana, W. (2021). Kosmetik Halal sebagai Lifestyle dan Kesehatan: Studi Takhrij dan Syarah Hadis. Pre-Print Kelas Menulis UIN Sunan Gunung Djati Bandung.

Fadila, A. (2021). Bersolek bagi Wanita Karir pada Waktu Ihdad dalam Perspektif Maqashid Syariah. Fakultas Syariah IAIN Bengkulu.

Habiba M. Assegaf, Christina Avanti, R. I. (2018). Efektivitas Pengawet pada Produk Lokal Eyeliner Waterproof terhadap Pertumbuhan Pseudomonas Aeruginosadan Candida Albicans yang Dijual di Pasar Blauran Kota Surabaya. Calyptra: Jurnal Ilmiah Mahasiswa Universitas 
Jurnal Riset Agama, Volume 1, Nomor 2 (Agustus 2021): 439-448

Syfa Nurhofipah/Itsmid sebagai Eyeliner dalam Kosmetika Dunia Muslim: Studi

Takhrij dan Syarah Hadis

Surabaya, 7(2), 1686-1699.

Intan Tri Yuniari, D. S. M. (2020). Pengaruh Pengaplikasian Teknik Eyeliner Terhadap Hasil Riasan Koreksi Mata Prominent Eyes untuk Pengantin Muslim Modifikasi. Jurnal Tata Rias, 09, 18-25.

M. Hafil Birbik. (2020). Takhrij Hadits (Metode Penelitian Sumber-sumber Hadits untuk Meminimalisir Pengutipan Hadits secara Sepihak). ArRisalah: Media Keislaman, Pendidikan Dan Hukum Islam, 8(1).

Qomarullah, M. (2016). Metode Takhrij Hadits Dalam Menakar Hadits Nabi. EL-Ghiroh: Jurnal Studi Keislaman, XI(02), 23.

Saltanera. (2015). Ensiklopedi Hadis Kitab 9 Imam. Lembaga Ilmu Dan Dakwah Publikasi Sarana Keagamaan, Lidwa Pustaka.

Soetari, E. (2015). Syarah dan Kritik Hadis dengan Metode Tahrij: Teori dan Aplikasi (2nd ed.). Yayasan Amal Bakti Gombong Layang.

Suparjan, N., \& Aisyah, S. (2020). Penggunaan Eyelash Extension bagi Perempuan Muslimah Perspektif Hukum Islam (Studi Kasus Salon di Kota Makassar). Jurnal Mahasiswa Hukum Keluarga Islam Universitas Islam Negeri Alauddin Makassar, 2, 69-82.

Ulfa, K. (2014). Studi Tematik Hadits tentang Tata Cara Tidur Nabi Muhammad SAW. UIN Walisongo Semarang.

Waliko, W. (2015). Konsep Iddah dan Ihdah bagi Wanita Karier yang Ditinggal Mati Suaminya (Tinjauan Ma'anil Hadis). Yinyang: Jurnal Studi Islam Gender Dan Anak, 10(1). 